\title{
Cerebral Langerhans Cell Histiocytosis: A Case Report
}

\author{
H. El Mansouri, S. Assagau, A. Benhammouda, F. Amenzouy, M. Oauli, N. Cherif Idrissi Ganouni \\ General Radiology Department, Mohamed VI University Hospital, Cadi Ayad University, Marrakesh, Morocco \\ Email: hana.elmansouri@gmail.com
}

How to cite this paper: El Mansouri, H., Assagau, S., Benhammouda, A., Amenzouy, F., Oauli, M. and Ganouni, N.C.I. (2019) Cerebral Langerhans Cell Histiocytosis: A Case Report. Open Access Library Journal, 6: e5115.

https://doi.org/10.4236/oalib.1105115

Received: December 13, 2018

Accepted: January 8, 2019

Published: January 11, 2019

Copyright $\odot 2019$ by author(s) and Open Access Library Inc.

This work is licensed under the Creative Commons Attribution International License (CC BY 4.0). http://creativecommons.org/licenses/by/4.0/

\begin{abstract}
Langerhans cells histiocytosis (LCH) is a disease caused by the proliferation and abnormal accumulation of Langerhans cells in different tissues and organs. It is a rare disease that still hides many of its mysteries as to its etiology and pathophysiology. The cerebral localization remains exceptional and dominated by hypothalamic-pituitary axis involvement. We report a case of a 20-year-old patient followed for acquired central diabetes insipidus with Panhypopituitarism and multiple dermatological lesions, who recently had visual acuity decline with progressive cerebellar syndrome in a state of apyrexia. Brain MRI showed multiples scattered plaques and nodular lesions involving the periventricular white matter, the basal ganglia, cerebellum, brainstem and cervical medulla. The two diagnoses suggested in this clinical presentation sarcoidosis with pituitary localization and cerebral Langerhans cells histiocytosis. A skin biopsy confirmed the diagnosis of langherans cell histiocytosis.
\end{abstract}

\section{Subject Areas}

Radiology \& Medical Imaging

\section{Keywords}

Langerhans Cells Histiocytosis, Brain, Imaging, MRI

\section{Case Presentation}

We report the case of a 20 -years-old patient followed for acquired central diabetes insipidus with Panhypopituitarism, who recently had visual acuity decline with progressive cerebellar syndrome in a state of apyrexia.

The clinical examination found multiple dermatological lesions composed of erythematous papules in the trunk and scalp and ulcerations of the oral mucosa. 
Brain MRI was requested regarding theses clinical signs.

Brain MRI showed multiple nodular and large confluent lesions of variable size up to $20 \mathrm{~mm}$. These lesions are found at peripheric and periventricular white matter, at the centrum semiovale, bilaterally at the external, internal capsules, lenticular nucleus and thalamus, at the cerebellar hemispheres andvermis, as well as at the pons, midbrain and cervical medulla (Figure 1).

They are T1isointense, T2/flair hyperintense (Figure 1(a) and Figure 1(b)). There were no perilesional edema and they do not exert any mass effect on nearby structures.

They enhance homogeneously after gadolinium injection (Figure 1(c) and Figure 1(d)). Nodular infiltration of the optic chiasm and the pituitary stalk with loss of spontaneous hyper-signal T1 of the neurohypophysis is noted. The maxillary sinuses and the mastoid cells are full of tissue enhanced after injection of gadolinium (Figure 2).

The two diagnoses suggested in this clinical presentation were: sarcoidosis with pituitary localization and cerebral Langerhans cells histiocytosis.

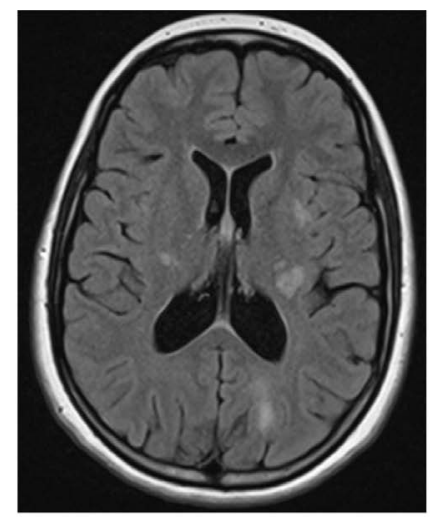

(a)

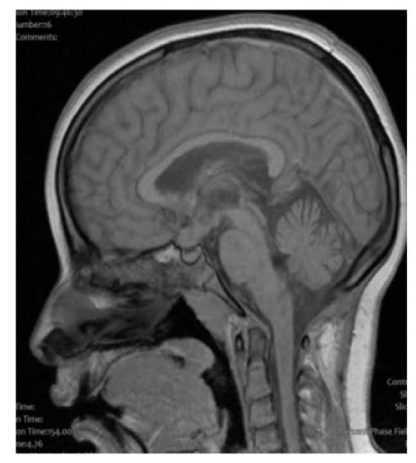

(c)

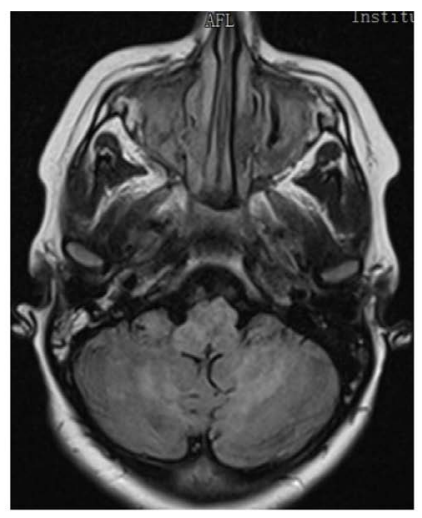

(b)

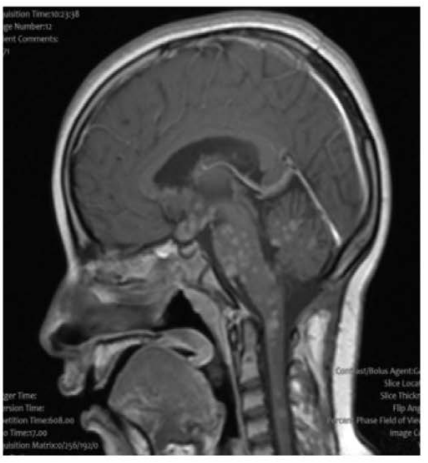

(d)

Figure 1. Brain MRI. Axial T2 (a) FLAIR (b) weighted images, and sagittal T1with and without contrast ((c), (d)) images show: nodular and large, confluent lesions, hyperintense in T2 Flair, iso intense in $\mathrm{T} 1$, homogeneously enhanced after gadolinium injection, involving periventricular and peripheric white matter, the centrum semiovale, bilateral basal ganglia, the cerebellum, as well as at the brainstem and cervical medulla. 


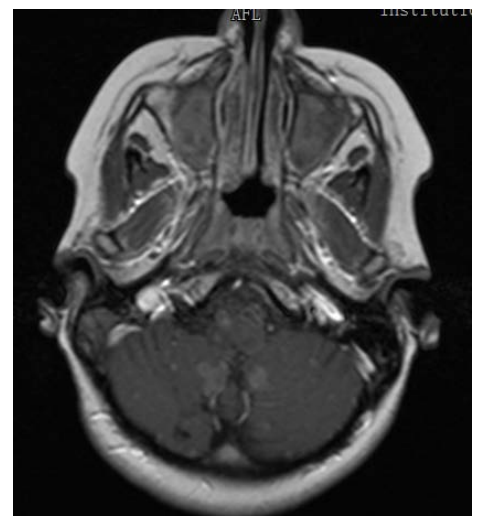

Figure 2. Brain MRI. Axial T1 with contrast showing: circumferential mucosal thickening of maxillary sinus and the right mastoid air cells, enhanced after injection of gadolinium.

A skin biopsy confirmed the diagnosis of Langerhans cells histiocytosis.

\section{Discussion}

Langerhans cells histiocytosis (LCH) is a disease caused by the proliferation and abnormal accumulation of Langerhans cells in different tissues and organs. It is a rare disease that still hides many of its mysteries as to its etiology and physiopathology [1].

This disease affects mainly the child and young adult, almost all the body may be affected by the disease, but the most common organs are bones, skin, lungs, liver, and ENT (ear, nose and throat) [2].

The cerebral localization remains exceptional and dominated by hypothalamic-pituitary axis involvement [3].

In hypothalamic-pituitary locations of Langerhans histiocytosis, diabetes insipidus is the endocrine most commonly found clinical presentation [4]. Its occurrence in the course of disease of other hormonal abnormalities is less frequent, but possible and classic. Hyperprolactinemia, growth hormone deficiency, thyroid insufficiency, hypogonadism with LH-FSH deficiency, corticotropic insufficiency, or even panhypopituitarism may occur [5].

The diagnosis of the cerebral localization of Langerhans cells histiocytosis is revolutionized by MRI.

In MRI there are mainly 3 types of abnormalities:

1) An enlargement of the diameter of the pituitary stalk, superior to $3 \mathrm{~mm}$ with a frank and homogeneous enhancement [6].

2) The disappearance of the spontaneous hyper-signal T1 of the neurohypophysis [6].

3) Abnormalities such as leukoencephalopathy that can be tentorial and sub-tentorial pons or cerebellar, often associated with involvement of the gray 
matter, particularly the nucleus dentatus [7].

Differential diagnoses vary by location: leukoencephalopathies for lesions on the central nervous system and germinomas, granulomatosis and autoimmune diseaseson the hypothalamic-pituitary axis.

ENT involvement is suggested when the external auditory canal, mastoid or labyrinthine system are touched [8]. Chronic otorrhea, mastoiditis, dizziness or acute deafness may be revealing signs of ENT histiocytosis.

\section{Conclusion}

Cerebral Langerhans cells histiocytosis corresponds to the proliferation and abnormal accumulation of Langerhans cells at all brain components; it must be suggested in any young patient presenting skin lesions with involvement of the hypothalamic-pituitary system with images of tentorial and sub-tentorial leukoencephalopathy.

\section{Conflicts of Interest}

The authors declare no conflicts of interest regarding the publication of this paper.

\section{References}

[1] Fraitag, S. (2010) Histiocytoses Langerhansiennes. Annales de Dermatologie et de Vénéréologie, 137, 163-66. https://doi.org/10.1016/j.annder.2009.12.009

[2] Veyssier-Belot, C. (2009) Histiocytoses Langerhansiennes. EMC-Traité de médecine AKOS, 3, 1-5. https://doi.org/10.1016/S1634-6939(09)49777-1

[3] Ajja, A. and Ammor, R. (2015) Histiocytose Cérébrale. Pan African Medical Journal, 22, 345.

[4] Tabarin, A., Corcuff, J.B., Dautheribes, M., Merlio, J.P., Cochet, C., Maire, J.P., Louail, C. and Roger, P. (1991) Histiocytosis X of the Hypothalamus. Journal of Endocrinological Investigation, 14, 139-145. https://doi.org/10.1007/BF03350286

[5] Fournier, C. and Scherpereel, A. (2004) Histiocytose X Pulmonaire et HypothalamoHypophysaire, diagnostiquée par biopsie cérébrale stéréotaxique [Endocrine and Pulmonary Histiocytosis: A Case Diagnosed through Stereotoxic Biopsy]. Revue des Maladies Respiratoires, 21, 141-145. https://doi.org/10.1016/S0761-8425(04)71246-2

[6] Nguyen, K. and Tazi, A. (2006) Histiocytose langerhansienne de l'adulte. Encyclopédie Orphanet.

[7] Donadieu, J. (2003) Histiocytose Langerhansienne. Encyclopédie Orphanet.

[8] Donadieu, J., Guyot-Goubin, A., Clavel, J. and Thomas, C. (2008) Présentation clinique et épidémiologie de l'histiocytose langerhansienne chez l'enfant. Archives de Pédiatrie, 15, 520-522. https://doi.org/10.1016/S0929-693X(08)71819-0 